\title{
Ascites Syndrome Associated with Hypothyroidism in a Brahma Chicken: a Case Study and Review of the Literature
}

\author{
Alexandru-Flaviu TĂBĂRAN ${ }^{1 *}$, Iancu MORAR ${ }^{1}$, Adrian Florin GAL $^{1}$, Roxana CORA ${ }^{1}$, Cornel CĂTOI ${ }^{1}$ \\ ${ }^{1}$ Faculty of Veterinary Medicine, University of Agricultural Science and Veterinary Medicine Cluj-Napoca, \\ Manastur Street. 3-5, 400372, Cluj-Napoca, Romania. \\ *corresponding author: alexandru.tabaran@usamvcluj.ro
}

Bulletin UASVM Veterinary Medicine 76(1)/2019

Print ISSN 1843-5270; Electronic ISSN 1843-5378

doi:10.15835/buasvmcn-vm: 2018.0048

\begin{abstract}
Ascites syndrome (AS) in chickens represents a major cause of mortality and the most frequent metabolicrelated cause of abattoir carcass condemnation in broilers. Susceptibility of broiler chickens to ascites is determined by a complex interaction between genetically-controlled factors (as high-rate metabolism and peculiarity of the cardiovascular system) and exogenous factors such as nutrition, and temperature. Endocrine imbalances, especially thyroid-gland dysfunctions, are currently regarded as key-elements in the development of AS. The current case represents the first spontaneous case of hypothyroidism (goiter) associated with AS in broilers, bringing additional arguments to the theory which claims the role of thyroid dysfunction in this syndrome. Further studies of spontaneous cases which must include assessment of the thyroid hormones need be performed in order to better understand the link between thyroid gland dysfunction and the cardiopulmonary changes in the context of AS in birds.
\end{abstract}

Key words: ascites syndrome, hypothyroidism, broilers, metabolic diseases, dilative cardiomyopathy

\section{Introduction}

Ascites syndrome in chickens, also known as pulmonary hypertension syndrome (PHS) (Hassanzadeh et al., 2014) or pulmonary arterial hypertension (PAH)(Wideman et al., 2013) occurs worldwide in meat-type fowl, representing one of the most important causes of mortality, and the most frequent metabolic-related cause of abattoir carcass condemnations in poultry (Herenda and Jakel, 1994; Charlton, 2000). In essence, the ascites syndrome in chickens is a form of pulmonary heart disease ("cor pulmonale"), the fluid accumulation in the abdominal cavity ("ascites") and occasionally pericardium being the ultimate result of a decompensated right-sided heart failure induced by pulmonary arterial hypertension.
Initially identified as a pathology solely related with high-altitude flocks (Cueva et al., 1974; Hall and Machicao, 1968) resembling in a certain degree the high-altitude pulmonary hypertension in cattle ("brisket-disease"), currently AS is regarded as a multifactorial pathology mediated by interaction between environmental, metabolic, nutritional and genetic factors (Decuypere et al., 2000; Hassanzadeh et al., 2014).

Regarding the etiology, the AS is induced by interactions between both endogenous factors (the genetically-selected high metabolic rate of fast-growing broilers, the reduced heart and lung size in the report to body weight, endocrine imbalances) and environmental elements as poor ventilation, high altitude, dietary factors (as high sodium and low dietary phosphorus 
levels, vitamin E/Se deficiencies) and even toxic elements as caffeine, mycotoxins, furazolidon (mainly experimental) and iodine antagonists or infectious agents as Enterococcus faecalis (Scheele et al., 1992; Decuypere et al., 2000; Tankson et al., 2001; Guo et al., 2007; Kamely et al., 2016). As pathogenesis, ascites is considered to be the result of cardiopulmonary failure determined by the imbalance between oxygen supply (Decuypere, et al. 2005) and the high oxygen demands which are required for the high growth rate of broilers. The genetic background role in the etiology of AS is linked with the altered metabolic requirements of broiler lines selected for high growth capacity (Decuypere et al., 2000; Hassanzadeh et al., 2014); broiler lines that combine both low food conversion ratio and fast growth rate were found to be particularly susceptible (Buys et al., 1999). The high heritability of ascites-related traits also highlights the role of genetic factors in the pathogenesis of AS (Pakdel et al., 2002).

Currently, one of the most intriguing theories regarding the pathogenesis of AS indicates the hypothyroidism as one of the primary causes of metabolic disturbance which finally will trigger the above-described events (Luger et al., 2002; Kamely et al., 2016). A reduced thyroid hormones activity, either by diminished synthesis or by disrupted peripheral metabolism of thyroxin (T4) in triiodothyronine (T3) is argued to be responsible for an inefficient thermoregulation and a mismatch between $\mathrm{O}_{2}$ delivery and tissue demands, which results in hypoxia and lung overload (Charlton, 2000; Hassanzadeh et al., 2014). The involvement of hypothyroidism in the pathogenesis of AS is well established under experimental conditions, although this pathogenesis is controversial and not supported by field clinical cases. This paper presents a case of hypothyroidism (goiter) in a Brahma chicken associated with ascites syndrome. From the author's knowledge, this represents the first spontaneous case confirming a pathogenic relation between hypothyroidism and AS in broilers. We present the gross and microscopical features of the case and discuss the possible etio-pathogenesis of AS from the perspective of comparative medicine.

\section{Materials and methods}

A five months old Brahma rooster with a history of poor weight gain was presented for necropsy to the Pathology Department of the University of Agricultural Sciences and Veterinary Medicine Cluj-Napoca, Romania. The harvested samples during necropsy were fixed in $10 \%$ neutralbuffered formalin (NBF) and further embedded in paraffin using the routine protocol. Histological sections were stained by hematoxylin and eosin (H\&E).

\section{Results and discussions}

During necropsy, external examination indicated marked cachexia, with reduced amount of body fat [body condition score 2/5 ( 1 = emaciated and 5 = obese)] (body weight $2.03 \mathrm{~kg}$ ) and marked muscle wasting. The thoracoabdominal cavity contained approximately $200 \mathrm{ml}$ of clear, orange-yellow ascitic fluid with many gelatinous clots (protein clots)(modified transudate). There was concurrent hydropericardium $(3 \mathrm{ml})$ and mild, diffuse edema of the abdominal wall and hind limbs. The liver was markedly enlarged, with round-irregular margins, thick-white, retractile capsule (Figure 1) and increased consistency. The heart measured $39 \mathrm{~g}$, with severe dilation and thinning of the right atrium and ventricle (RA and RV). Following the removal of the postmortem clot, the RA wall presented as a thin translucent membrane, crossed by delicate reticular-opaque areas (pectinate muscles). The atrioventricular valve showed multifocal endocardiosis: coalescing round to oval, white-myxoid nodules measuring up to $2 \mathrm{~mm}$ in diameter (Figure 1, E). In birds myxoid degeneration of the endocardium (endocardiosis) is most frequently located in the right atrioventricular valve. It is occasionally associated with cardiac (valvular) failure, but as in our case, most frequently induced by the local hemodynamic and mechanical stress (Julian, 1993; Julian 2002).

The lungs showed bilateral, diffuse congestion (mild) and edema (marked) (Figure 2, A). The thyroid glands were enlarged, with glassy, redbrown, homogenous appearance on cut section (Figure 2, B). The thyroid weight was 1,34 $\mathrm{g}$ for the left side and $0,9 \mathrm{~g}$ for the right-sided gland. 


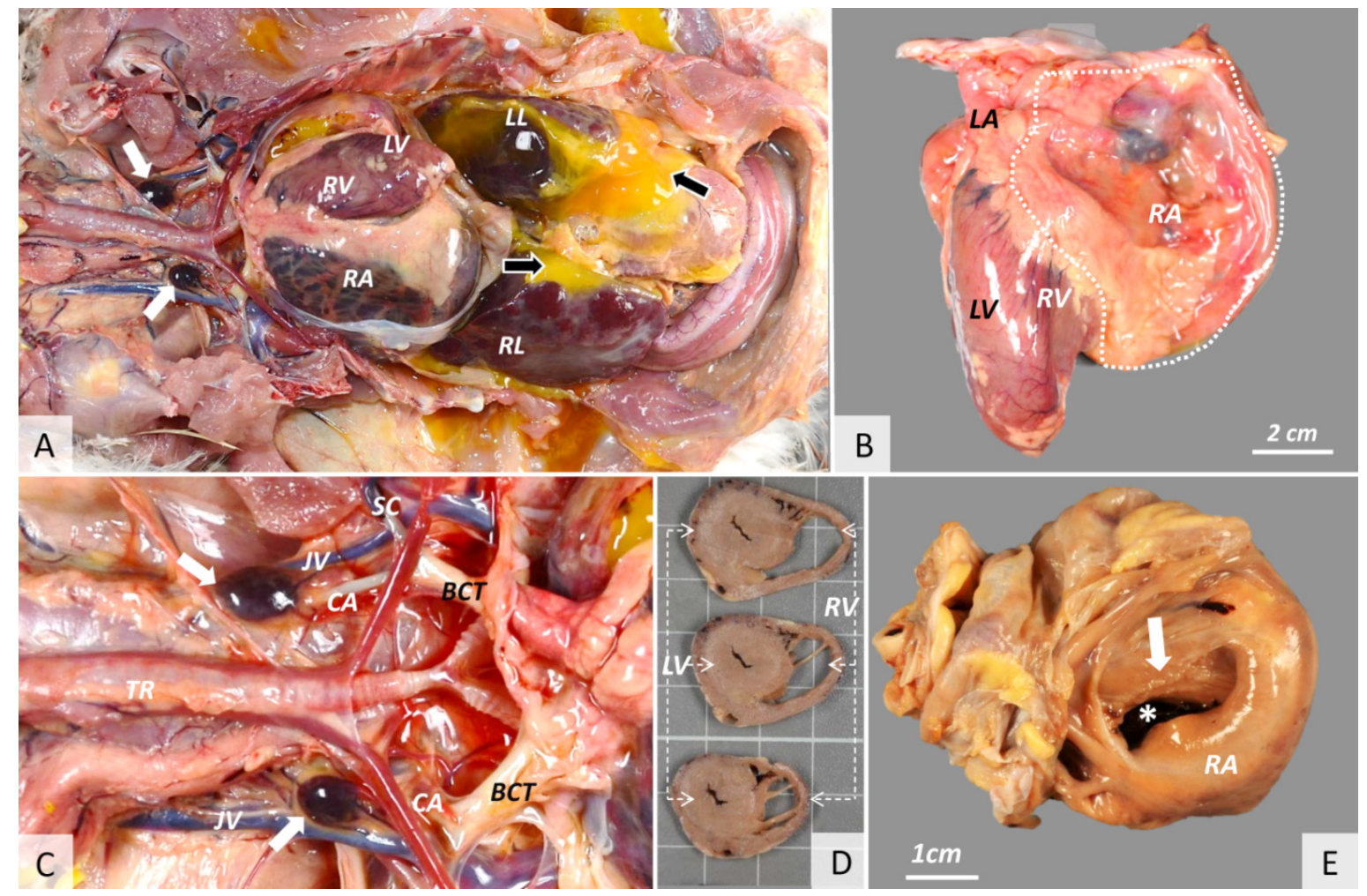

Figure 1. Ascites Syndrome in a Brahma Chicken. Image A: Gross view of the cervical area, pericardial and thoracoabdominal cavity, showing abdominal accumulation of an orange-yellow liquid rich in gelatinous clots (black arrows) (modified transudate), severe distension of the right atrium and ventricle and bilateral enlargement of the thyroids (white arrows). Note the hepatomegaly and extensive fibrosis affecting both right and left liver lobes (RL and LL). Image B: Heart after removal of the postmortem clot, showing marked dilation and thinning of the right atrium and ventricle. Image $\mathbf{C}$ : Detail of the dissected cervical area showing the bilateral, diffuse enlargement of the thyroids (white arrows). Image D: Cross section of the heart: marked distended right ventricle lined by a thin free wall. Image E: dorsal view of the right atrioventricular opening

(asterisk) and valve: multifocal nodular thickening of the endocardium (endocardiosis-arrow).

Abbreviations: $\mathrm{TR}=$ Trachea; $\mathrm{CC}=$ common carotid artery; $\mathrm{SC}=$ subclavian artery; $\mathrm{CA}=$ common carotid artery; $\mathrm{BCT}=$ brachiocephalic trunk; JV=jugular vein; $\mathrm{RA}=$ right atrium; $\mathrm{RV}=$ right ventricle; $\mathrm{LV}=$ left ventricle, $\mathrm{LA}=\mathrm{left}$ atrium.

Histologically, the lung showed diffuse congestion of the parabronchi, and a small amount of pale-eosinophilic material within the parabronchi's lumen (Figure 2, C). The thyroidal lesions were consistent with diffuse bilateral colloidal goiter: thyroid follicles were diffusely enlarged, distended with homogenouseosinophilic colloid, and lined by flat to low cuboidal follicular epithelial cells with few resorption lacunae (Figure 2, D).

The high metabolic rate in fast-growing broilers induced by extreme genetic selection is responsible for a high oxygen consumption, which especially when associated with decreased oxygen tension or low-ambient temperatures induce a cascade of events which combine: 1) tissue hypoxia; 2) hematocrit elevation; 3) increased vascular lung pressure (pulmonary arterial hypertension mainly due to an inappropriate pulmonary vasoconstriction); 4) right ventricular hypertrophy; 5) right atrioventricular valve insufficiency; 6) right-cardiac volume overload, dilation, and right ventricular failure; 7) systemic circulation hypertension and finally, 8) hydrostatic edema and cavitary effusions which define the AS (Decuypere et al., 2000; Baghbanzadeh and Decuypere, 2008; Hassanzadeh at al., 2014).

From the perspective of comparative pathology, the ascites and myxedema represent a well-known complication of hypothyroidism in 


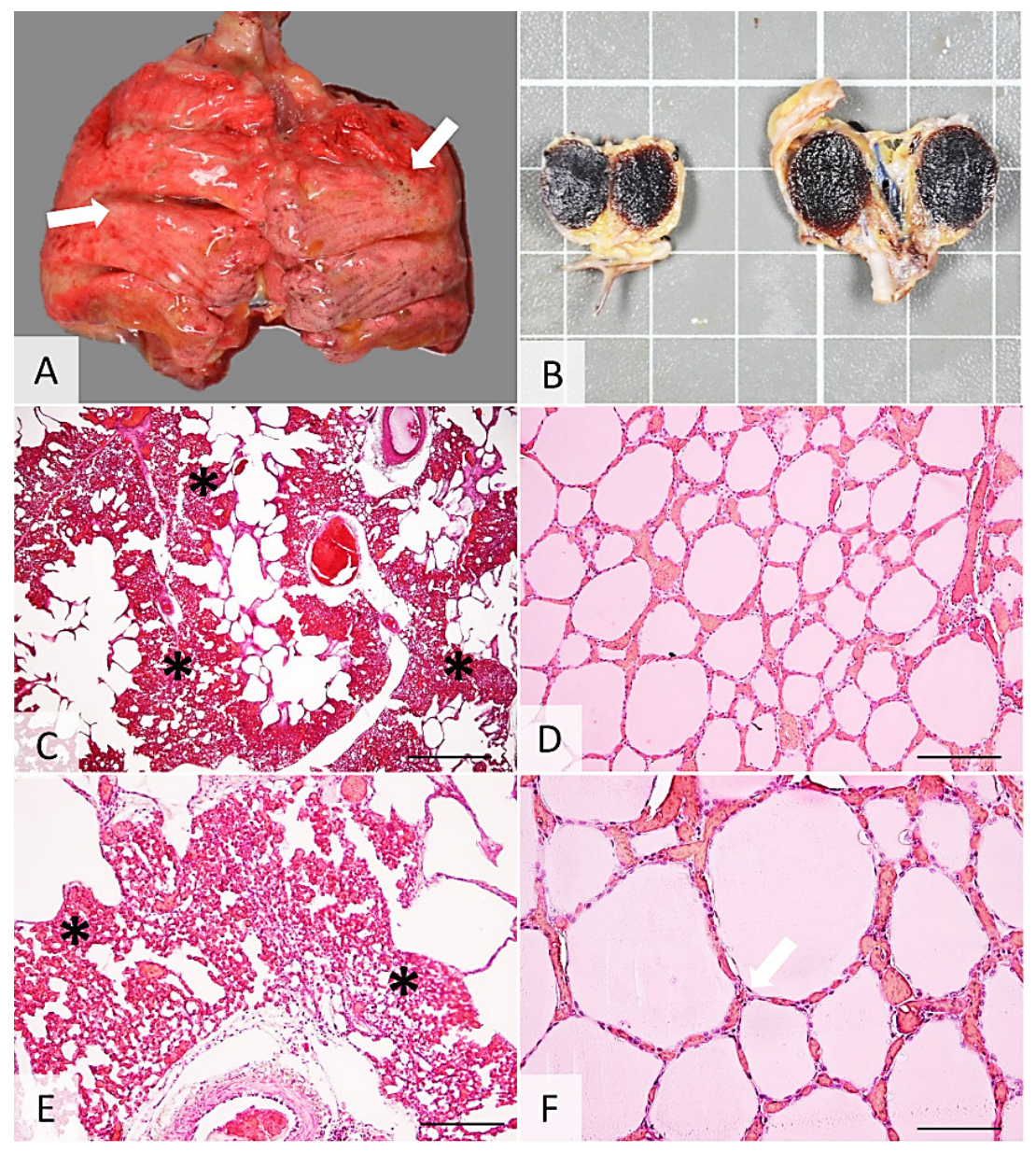

Figure 2 Ascites Syndrome in a Brahma Chicken. Image A: Diffuse lung congestion and edema (arrows); Image B: Goiter- bilateral enlargement of the two thyroids, with a glassy, red-brown, homogenous appearance on cut section. Each grid represents $1 \mathrm{~cm}$. Image C: histological features of the lung, showing diffuse congestion of the pulmonary parenchyma (asterisks). Image D: histological features of the thyroid, showing variable-sized thyroid follicles lined by a flat epithelium. H\&E, obx10 for image $C$ (scale bar $=200 \mu \mathrm{m}$ ), obx20 for image $\mathrm{D}$ (scale bar $=100 \mu \mathrm{m})$.

humans (Khalid et al., 2016). This association was also confirmed in dogs, in which these morbidities coexist in at least in on case (Flood and Hoover, 2009) in which the cavitary fluid accumulation was attributed mainly to the impaired cardiac function. In this context, ascites follows the same pathologic features described in AS in chickens: hypoxia; hypothermia (following the reduction of the basal metabolism); hydropericardium and pulmonary edema (which results from fluid and electrolyte imbalance) followed by cardiac dilation and failure (Scheele et al., 1992). Anemia, one of the main symptoms in humans is often replaced in chicken by erythrocytosis, but this finding is inconstant and has a low predictive value of AS evolution (Scheele et al., 2003).
The evolution from right ventricular hypertrophy to right atrioventricular valve insufficiency is the process which transforms the initial cardiopulmonary pathology into systemic hypertension which finally will determine the hydrostatic edema. Compared with mammals, this process is accelerated in birds because of a peculiarity of the heart anatomy: the muscular structure of the right atrioventricular valve (RAV). Although having a similar function as in mammals, in birds RAV represents an extension of the right ventricular musculature and thus any significant change in the volume of the ventricular wall readily affects the systolic valvular closure, inducing valvular regurgitation, volume overload and stasis (Charlton, 2000). 
Goiter (hypothyroidism) represents the most frequent pathology affecting the thyroid glands in birds, being described frequently in psittacidae (mainly budgerigars, cockatiels) and occasionally in poultry. In birds is diagnosed in both hyperplastic and colloid forms (the first subtype is the most frequent form diagnosed in the companion birds) (Glazener and Jull, 1946; Schmidt and Reavill, 2008; Loukopoulos et al., 2015). As in mammals, in birds goiter has mainly a nutritional cause, being associated in most of cases with the intake of insufficient amounts of Iodine, consumption of iodine metabolism antagonist (goitrogenic substances, e.g. thiouracil), or rarely genetically induced deficiencies in thyroid hormones biosynthesis (Sasipreeyajan and Newman, 1988; Schmidt and Reavill, 2002), followed by increment of thyroid-stimulating hormone (TSH) synthesis and hyperplasia of the thyroid gland. The bilateral enlargement of the thyroid gland (in our case with an overall thyroid/body weight ratio of 0,110 ) confirms the diagnosis of hypothyroidism (goiter) (Andrews and Schnetzler, 1946; Andrews and Bohren, 1947; Parmer et al., 1987). Histopathological demonstration the colloid subtype of goiter (regressive phase of the hyperplastic goiter) indicates that in our case the TSH hyper-stimulation ceased by the time of necropsy (Zachary, 2017).

Ascitic chickens induced by hypothyroidism is frequently associated with a high corticosterone plasma concentration due to a marked stress response, but the exact association between these pathologies is unclear (Luger et al., 2002), hypothetically being linked with red blood cell production in which both corticosterone and Triiodothyronine (T3) seems to be involved (Luger et al., 2002). An interesting fact is that artificialinduced hyperthyroidism can also be associated with the development of ascites in broilers (Decuypere et al., 1994; Hassanzadeh at al., 1997). This involvement of hypothyroidism in broilers ascites is poorly understood but attributed by several studies to the metabolically imbalances (mainly increment of the basal metabolism and thus of the $\mathrm{O}_{2}$ needs) induced by the excess thyroid hormones (Decuypere et al., 2000; Luger et al., 2001).

\section{Conclusion}

This case of ascites syndrome in a Brahma chicken represents the first spontaneous case confirming a pathogenic relation between hypothyroidism and ascites syndrome in broilers. Further studies which must include measurement of the thyroid hormones in order to assess the dynamics of thyroid gland function need be performed in order to better understand the link between the hypothyroidism (goiter) and the cardiopulmonary function in the context of ascites syndrome in birds.

Acknowledgments. This research did not receive any specific grant from funding agencies in the public, commercial, or not-for-profit sectors.

Declaration of interests. The authors report no conflict of interest.

\section{References}

1. Andrews F N, Bohren B B (1947). Influence of Thiouracil and Stilbestrol on Growth, Fattening, and Feed Efficiency in Broilers. Poultry Science, 26(5): 447-452.

2. Andrews F N, Schnetzler E E (1946). Influence of Thiouracil on Growth and Fattening in Broilers. Poultry Science, 25(2): 124-129.

3. Baghbanzadeh A, Decuypere E (2008). Ascites syndrome in broilers: physiological and nutritional perspectives. Avian Pathology 37(2): 117-126.

4. Buys N, Scheele C W, Kwakernaak C, van der Klis J D, Decuypere E (1999). Performance and physiological variables in broiler chicken lines differing in susceptibility to the ascites syndrome: 1. Changes in blood gases as a function of ambient temperature. British Poultry Science, 40(1): 135-139.

5. Charlton B R (2000). Avian disease manual (5th edition). Kennett Square: American Association of Avian Pathologists (Chapter 6-Miscellanous Diseases).

6. Cueva S, Sillau H, Valenzuela A, Ploog H (1974). High altitude induced pulmonary hypertension and right heart failure in broiler chickens. Veterinary Science, 16(3): 370374.

7. Decuypere E, Buyse J, Buys N (2000). Ascites in broiler chickens: exogenous and endogenous structural and functional causal factors. World's Poultry Science Journal, 56(04): 367-377.

8. Decuypere E, Hassanzadeh M, Buys N, Buyse J (2005). Further insights into the susceptibility of broilers to ascites. The Veterinary Journal, 169(3): 319-320.

9. Decuypere E, Vega C, Bartha T, Buyse J, Zoons J, Albers G A A (1994). Increased sensitivity to triiodothyronine ( $T$ 3) of broiler lines with a high susceptibility for ascites. British Poultry Science, 35(2): 287-297.

10. Flood J A, Hoover J P (2009). Improvement in myocardial dysfunction in a hypothyroid dog. The Canadian Veterinary Journal, 50(8): 828-834. 
11. Glazener E W, Jull M A (1946). Effects of Thiouracil, Desiccated Thyroid, and Stilbestrol Derivatives on Various Glands, Body Weight, and Dressing Appearance in the Chicken. Poultry Science, 25(3): 236-241.

12. Guo J L, Zheng Q H, Yin Q Q, Cheng, W, Jiang Y B (2007). Study on Mechanism of Ascites Syndrome of Broilers. American Journal of Animal and Veterinary Sciences, 2(3): 62-65.

13. Hall S A, Machicao N (1968). Myocarditis in broiler chickens reared at high altitude. Avian Diseases, 12(1): 75-84.

14. Hassanzadeh M, Buyse J, Toloei T, Decuypere E (2014). Ascites Syndrome in Broiler Chickens: A Review on the Aspect of Endogenous and Exogenous Factors Interactions. The Journal of Poultry Science, 51(3): 229-241.

15. Hassanzadeh M L, Buys N, Dewil E, Rahimi G, Decuypere E (1997). The prophylactic effect of vitamin C supplementation on broiler ascites incidence and plasma thyroid hormone concentration. Avian Pathology, 26(1): 33-44.

16. Herenda D, Jakel O (1994). Poultry abattoir survey of carcass condemnation for standard, vegetarian, and free range chickens. The Canadian Veterinary Journal, 35(5): 293-296.

17. Julian R J (1993). Ascites in poultry. Avian Pathology, 22(3): 419-454

18. Julian R J (2002). The Avian Cardiovascular System. Kennett Square. American Association of Avian Pathologists. https://aaap.memberclicks.net/assets/ Slides/cardiovascular.pdf Accessed 01.27.2019.

19. Kamely M, Karimi Torshizi M A, Rahimi S (2016). Blood biochemistry, thyroid hormones, and performance in broilers with ascites caused by caffeine. Poultry Science, 95(11): 2673-2678.

20. Khalid S, Asad-Ur-Rahman F, Abbass A, Gordon D, Abusaada K (2016). Myxedema Ascites: A Rare Presentation of Uncontrolled Hypothyroidism. Cureus, 5;8(12): 1-6.

21. Loukopoulos P, Bautista A C, Puschner B, Murphy B, Crossley B M, Holser I, Uzal F A (2015). An outbreak of thyroid hyperplasia (goiter) with high mortality in budgerigars (Melopsittacus undulatus). Journal of Veterinary Diagnostic Investigation, 27(1): 18-24.

22. Luger D, Shinder D, Rzepakovsky V, Rusal M, Yahav S. (2001). Association Between Weight Gain, Blood
Parameters, and Thyroid Hormones and the Development of Ascites Syndrome in Broiler Chickens. Poultry Science, 80(7): 965-971.

23. Luger Dror, Shinder D, Yahav S (2002). Hyper- or hypothyroidism: its association with the development of ascites syndrome in fast-growing chickens. General and Comparative Endocrinology, 7. 127(3): 293-299.

24. Pakdel A, Van Arendonk J, Vereijken A, Bovenhuis H. (2002). Direct and maternal genetic effects for ascitesrelated traits in broilers. Poultry Science, 81(9): 12731279.

25. Parmer T G, Carew L B, Alster F A, Scanes C G (1987). Thyroid Function, Growth Hormone, and Organ Growth in Broilers Deficient in Phosphorus. Poultry Science, 66(12): 1995-2004.

26. Sasipreeyajan J, John A Newman (1988). Goiter in a Cockatiel (Nymphicus hollandicus). Avian Diseases, 32(1): 169-172.

27. Scheele C W, Decuypere E, Vereijken P F G, Schreurs F J G (1992). Ascites in Broilers.: 2. Disturbances in the Hormonal Regulation of Metabolic Rate and Fat Metabolism. Poultry Science, 71(12): 1971-1984.

28. Scheele C W, van Der Klis J D, Kwakernaak C, Buys N, Decuypere E. (2003). Haematological characteristics predicting susceptibility for ascites. 2. High haematocrit values in juvenile chickens. British Poultry Science, 44(3): 484-489.

29. Schmidt R E, Reavill D R (2002). Thyroid Hyperplasia in Birds. Journal of Avian Medicine and Surgery, 16(2): 111114.

30. Schmidt R E, Reavill D R (2008). The Avian Thyroid Gland. Veterinary Clinics of North America: Exotic Animal Practice, 11(1): 15-23.

31. Tankson J D, Thaxton J P, Vizzier-Thaxton Y (2001). Pulmonary Hypertension Syndrome in Broilers Caused by Enterococcus faecalis. Infection and Immunity, 69(10): 6318-6322.

32. Wideman R F, Rhoads D D, Erf G F, Anthony N B (2013). Pulmonary arterial hypertension (ascites syndrome) in broilers: A review. Poultry Science, 92(1): 64-83.

33. Zachary JF (2017). Pathologic Basis of Veterinary Disease (6th ed.). Saint Luis: Elsevier Health Sciences, (Chapter 12). 